\title{
Capital fictício e educaÇão No BRASIL: UM ESTUDO SOBRE A LÓGICA CONTEMPORÂNEA DA PRIVATIZAÇÃO
}

\author{
FICTITIOUS CAPITAL AND EDUCATION IN BRAZIL: \\ A STUDY ON THE CONTEMPORARY LOGIC OF PRIVATIZATION
}

\author{
Luciana Sardenha Galzerano \\ Doutoranda da faculdade de Educação da Universidade de São Paulo. São Paulo - SP - Brasil \\ lucianasgalzerano@gmail.com
}

Lalo Watanabe Minto

Doutor em Educaçáo pela Universidade Estadual de Campinas, docente na mesma instituição. São Paulo - SP - Brasil lalo@unicamp.br

\begin{abstract}
Resumo: O objetivo do estudo é apresentar algumas das tendências que têm caracterizado a privatização da educação no contexto da crescente mercantilizaçáo e vinculaçáo com as formas do capital fictício. Trata-se de uma análise predominantemente teórica, em que se busca interseccionar contribuiçóes de campos como a educação e a economia, reunindo elementos que fundamentem uma compreensão abrangente e crítica sobre a natureza complexa da privatização. O referencial teórico utilizado é o marxista, com apropriação da obra original de Marx, bem como dos debates sobre o processo de acumulação contemporânea e da crise estrutural, e de autores que debatem os processos de privatização no campo educacional. Ao nos apropriarmos dessa literatura, destacamos que existem três dimensôes essenciais para compreender a fase mais recente da privatização da educação: a centralidade do capital fictício, os movimentos de concentração e centralização de capitais e as disputas pelos fundos públicos. Nas consideraçóes finais, apontamos que a predominância da financeirizaçáo em grande parte do setor educacional brasileiro representa um desenvolvimento da lógica da acumulação capitalista contemporânea.
\end{abstract}

Palavras-chave: Capital Fictício. Educação. Financeirização. Privatização.

Abstract: This study aims to present some of the trends that have characterized the privatization of education in the context of increasing commodification and linkage with the forms of fictitious capital. It is a predominantly theoretical analysis that seeks to intersect contributions from fields such as education and economics, gathering elements that support a comprehensive and critical understanding of the complex nature of privatization. Our main theoretical reference is the Marxism, with the appropriation of Marx's works, as well as the debates about the process of contemporary accumulation and the structural crisis, and authors who debate the privatization processes in the educational field. When we appropriate this literature, we emphasize that there are three essential dimensions to understanding the most recent phase of the privatization of education: the centrality of fictitious capital, movements of concentration and centralization of capital, disputes over public funds. In the final considerations, we point out that the 
predominance of financialization in much of the Brazilian educational sector represents a development of the logic of contemporary capitalist accumulation.

KeYwords: Fictitious Capital. Education. Financialization. Privatization.

A tendência global de privatização da educação vem sendo apontada por diversos estudos e autores do campo educacional, além de trabalhos que interseccionam análises sobre a educação, as políticas sociais e suas determinaçôes econômicas ${ }^{1}$. Em diálogo com as vertentes críticas dessa produção, e também com os estudos que têm se dedicado à análise teórica marxista da fase contemporânea da acumulação capitalista, bem como de sua crise estrutural, neste artigo nos apropriamos dessa literatura e destacamos três das dimensôes que consideramos essenciais para compreender a fase mais recente da privatização da educação. Sáo elas: a centralidade do capital fictício, os movimentos de concentração e centralização de capitais e as disputas pelos fundos públicos.

Trata-se de analisar as formas pelas quais o capital viabiliza, na sociedade capitalista contemporânea, a geração de valor para se acumular e se concentrar. Esse é um movimento que tem no Estado um de seus agentes fundamentais, portanto, a privatização da educação não é vista numa ótica jurídico-formal, como mero deslocamento entre as "fronteiras" do público/estatal e do privado/não estatal.

$\mathrm{Na}$ fase contemporânea do modo de produção capitalista tem-se observado, ademais, um movimento de reversão de conquistas e direitos sociais por todo o mundo; um processo que impinge uma retração da esfera pública e tem como veículo um arcabouço ideológico que busca se legitimar demandando a 'redução' do Estado e a consequente ampliação da margem de controle e regulação desses espaços pela lógica do capital. $\mathrm{O}$ que ocorre, de fato, é uma minimização das funções públicas do Estado, abrindo caminho para um fortalecimento da sua dimensão coercitiva e repressiva. (HARVEY, 2012, p. 87) ${ }^{2}$

Como é a proteção das corporaçóes privadas e de seus interesses que está em jogo, e o capital precisa apropriar-se de todos os espaços possíveis de acumulação e realização de valor, fazer frente à crise, do ponto de vista do Estado, significa tratar a pobreza e as formas de manifestação da 'questão social' numa ótica de criminalização crescente ${ }^{3}$. A violência desencadeada pela reestruturação é, a um só tempo, física, simbólica e política; os 
conflitos sociais provenientes das próprias contradições do desenvolvimento capitalista passam a ser decididos

[...] ao sabor dos interesses voláteis do capital financeirizado: é como se não houvesse regras; o Estado é chamado a atuar, com a violência que for necessária, para garantir a acumulação, razão pela qual o "ajuste fiscal" não é colocado no plano da negociação mas da imposiçâo. (MINTO, 2018a, p. 295, grifo do autor).

Em sintonia com as teses de Harvey, Paulani (2008, p. 121) afirma que um expediente típico dos processos de acumulação primitiva é acionado:

$\mathrm{O}$ resgate desses expedientes violentos minoraria as consequências da sobreacumulação, visto que desbravaria "territórios" para a acumulação de capital antes fora de seu alcance. Em outras palavras, estaríamos agora numa época de "acumulação por espoliação", em que se aliam o poder do dinheiro e o poder do Estado, que dela participa sempre (ou diretamente, ou por conveniência, ou por omissão). Vários são os exemplos desse tipo de processo [...] Em todos eles, sem a participação do Estado, sem sua administração em benefício do business, esse tipo de acumulação primitiva não existiria.

O objetivo deste estudo é apontar algumas das tendências que têm caracterizado a privatização da educação (básica e superior) nesse contexto de crescente mercantilização e vinculação com as formas predominantes do capital fictício.

\section{Centralidade do capital fictício na fase de crise estrutural}

Gomes (2015a, p. 18) afirma que a crise atual foi ocasionada pela "reduçáo da rentabilidade do capital produtivo e a busca por compensar a perda de oportunidades de valorização, pela via da especulação." São desordens econômicas que atingem sucessivamente diversos países e que, após três 
décadas, se veem agravadas quantitativa e qualitativamente: após 2006 e, especialmente, em 2008, há uma evolução exponencial, com a emergência da crise desencadeada no mercado imobiliário dos Estados Unidos, espalhando-se a partir do centro do sistema para todo o mundo. (HERRERA, 2015)

A atual etapa da acumulação capitalista, portanto, é distinta das anteriores, especialmente daquele período que vai do pós-2a Guerra Mundial a meados da década de 1970. O que define essa especificidade é a dominação do capital especulativo parasitário sobre todas as outras formas de capital (GOMES, 2015a, p. 14-15), e não propriamente as questôes ligadas à globalização, às consequências da reestruturação produtiva e, ainda, das políticas neoliberais sobre as formas de organização do Estado e da vida social.

Vários autores ${ }^{5}$ têm se dedicado ao estudo dos recentes processos de crise e daquilo que alguns nomeiam de financeirização. A nosso ver, para compreendê-los é fundamental recorrer à categoria marxiana capital fictício ${ }^{6}$. Se as ideias de Marx sobre essa temática não estavam 'concluídas' e, evidentemente, muitas coisas mudaram desde a sua época, é certo que o autor nos legou um arcabouço teórico essencial para a apreensão dos movimentos fictícios do capital.

No livro III d'O Capital, Marx trata da evolução do sistema de crédito capitalista em ligação com o capital portador de juros ${ }^{7}$. Em princípio, o capital-dinheiro aparece como um empréstimo realizado por um prestamista a um capitalista individual, que precisa de capital para reinvestir na produção. O valor de uso do dinheiro, portanto, além de ser dinheiro, é o de funcionar como capital, isto é, apropriar-se de uma parcela do valor já produzido socialmente. Nessa transação, o retorno do capital "não parece mais resultar do processo de produçáo e tudo se passa como se o capital emprestado nunca tivesse perdido a forma dinheiro." (MARX, s/d, p. 403) O capital portador de juros, portanto, é uma mercadoria cujo valor de uso é produzir mais-valia - para quem o possui e para quem o vai tomar emprestado. O proprietário desse capital não deixa de ter a sua propriedade, sendo, portanto, o 'ponto de chegada' do processo de valorização: não há compra nem venda convencionais. Por isso, no caso do capital portador de juros, seu elemento distintivo estava na "forma externa do retorno, dissociada do ciclo mediador” (MARX, s/d, p. 401), criando a ilusão de que dinheiro produz dinheiro e que o lucro desse prestamista era proveniente 
de um contrato jurídico estabelecido entre ambos, mas não da produção. Tem-se aí o ápice do fetichismo. (MARX, s/d, p. 403)

Uma vez constituída a forma do capital portador de juros e desenvolvido o sistema financeiro (concentração do capital-dinheiro; expedição de títulos de propriedade sobre ganhos que, num primeiro momento, estão vinculados a atividades reais e concretas), as movimentaçóes de capitaldinheiro podem se expandir de modo a ultrapassar sua conexão com a base material, criando o que Marx chama de uma existência fictícia. Criam-se situaçóes (na esfera da circulação) que tornam ainda mais efêmera a percepção da conexão real existente entre o processo efetivo de valorização do capital e as formas de papéis e títulos que concedem direitos sobre parcelas desses ganhos. O capital é fictício pois, em grande medida, não tem existência efetiva, por isso, pode circular mudando de mãos sem que sua lógica de valorização obedeça necessariamente àquela operada na produção real.

Carcanholo e Sabadini (2009, p. 43) alertam, porém, que embora o capital fictício apareça como consequência do capital portador de juros, ambos são diferentes:

[...] o capital a juros não pode ser confundido com o capital fictício que gera. Aquele corresponde a uma riqueza real que foi produzida sob a forma de excedente; este último é puramente fictício do ponto de vista global. O capital fictício gerado nessas condiçôes é como o 'reflexo em um espelho' do capital a juros. São dois capitais diferentes: um é real e o outro submetido à dialética real/fictícia.

Para os autores, o capital fictício muda de caráter ao transformarse de polo dominado em polo dominante, por isso o nomeiam capital especulativo parasitário e denominam a atual fase desse modo de produção de capitalismo especulativo. A essa fase corresponde, também, uma nova forma: a dos lucros fictícios. Tal qual o capital fictício, esses também devem ser analisados dialeticamente: sob o ponto de vista individual, são reais, mas, na totalidade, não possuem realidade substantiva, pois não advêm do excedente-valor produzido pelo trabalho. Ainda segundo os autores, esses lucros “[...] são pura 'fumaça'. Da mesma maneira que apareceram como mágica, da noite para o dia, podem desaparecer a qualquer 
momento, em razão das oscilações especulativas dos valores dos ativos." (CARCANHOLO; SABADINI, 2009, p. 50)

Os 'lucros fictícios', complementam Carcanholo e Sabadini (2009), aparecem como estratégia para se contrapor à tendência de queda da taxa de lucro, mas não se sustentam para a continuidade da acumulação capitalista sem um incremento adicional da exploração do trabalho. Ou seja, para que outros setores, como o financeiro, onde náo se produz o valor mantenham sua dinâmica de ampliação é necessário que as fronteiras da exploração da força de trabalho, onde efetivamente se produz o valor, também o sejam.

O processo de reestruturação capitalista foi uma expressão dessas tentativas de recuperação dos níveis de acumulação obtidos nos anos do pós-guerra, via ampliação crescente das "formas fictícias do capital." (MARQUES; NAKATANI, 2013, p. 65). Circulando mais rápido e facilmente, houve um aumento do "fluxo internacional de capitais para as economias onde essas condiçóes eram mais favoráveis, com destaque para a taxa de exploração da força de trabalho elevada." (id.ib.)

Os impactos desse processo sobre a economia brasileira foram intensos: ampliou-se a heterogeneidade estrutural de nossa base produtiva, alterando igualmente as formas de inserção das classes e fraçóes de classes locais na dinâmica do novo padrão de acumulação de capital em escala mundial. Apesar de sua tardia liberalização econômica e financeira nos anos 1990, o Brasil se tornou um dos destinos preferenciais do capital internacional, cuja entrada no após Plano Real passou a ser concentrada cada vez mais no setor de serviços (MARQUES; NAKATANI, 2013, p. 73-76). Nos governos FHC, Lula e Dilma predominou uma orientação macroeconômica comum; setores que podiam ser capturados pelos grandes capitais internacionais sofreram os maiores impactos e, nesse sentido, a neoliberalização do país também foi um processo de desnacionalização e de desindustrialização. Era a ideia de que o país

pegaria o bonde da história pela via do comércio exterior. [...] Mas o Brasil entrou no bonde da história por outra porta e transformou-se em plataforma de valorização financeira internacional, bem em linha com o espírito rentista e financista dos dias que correm. Em seu papel, juntamente com sua função de produzir bens de baixo valor agregado e, de preferência, com a 
utilização de mais-valia absoluta [...] completa a caracterização da participação do Brasil na divisão internacional do trabalho do capitalismo contemporâneo. (PAULANI, 2008, p. 131-132)

Essa forma de inserção na economia mundial no âmbito da predominância do capital fictício não se desenvolveu sem conflitos, mas foi predominante o suficiente para propiciar, ao final, uma aceleração e um aprofundamento das relaçôes de dependência, estruturais à nossa condição periférica. Houve mudanças pontuais entre os governos brasileiros, mas não a ponto de desautorizar aquelas medidas governamentais que foram tomadas estrategicamente para conferir flexibilidade ao capital: desterritorialização da produção; desregulamentação dos mercados, principalmente o financeiro; diminuição de proteção ao trabalho; ataque aos sindicatos; redução e privatização parcial de sistemas de seguridade social, de empresas e serviços estatais. Os setores de serviços sociais transformaram-se em grandes oportunidades de acumulação de capital (PAULANI, 2008; BRAZ NETTO, 2009) e organismos internacionais como Banco Mundial, OCDE e FMI tiveram importante contribuição na disseminação de propostas privatistas para a educação. (ROBERTSON; VERGER, 2012)

\section{Concentração e centralização de capitais na educaçáo}

$\mathrm{Na}$ área educacional brasileira esse processo tem ocorrido via formaçáo de grandes conglomerados, com envolvimento direto com o setor financeiro. É lícito lembrar que o Conselho Administrativo de Defesa Econômica (Cade) autorizou às empresas educacionais o ingresso em mercado de açôes e que, além disso, a existência de instituiçóes com fins lucrativos possui respaldo legal. (SGUISSARDI, 2015, p. 871)

A conexão entre as atividades educacionais e as formas fictícias de capital pode ser observada pela presença dos chamados fundos private equity e pela abertura de capital das empresas que atuam na área (CARVALHO, 2013, p. 770). As primeiras ofertas públicas iniciais (Initial public offer) são 
de 2007 e, desde então, têm prosperado na educação brasileira, conforme já sinalizava a Reuters em 2013:

O setor educacional brasileiro tem crescido a taxas de dois dígitos nos últimos anos, rendendo 11 bilhôes de dólares ao ano [...] Banqueiros disseram à Reuters que as ofertas públicas iniciais se transformaram em uma viável estratégia de captação de recursos para os operadores universitários, escolas de línguas e fornecedores de sistemas de aprendizagem, assim como as fusões e aquisiçôes impulsionaram a atividade ao longo dos últimos dois anos. (PARRA-BERNAL, SCHINCARIOL, 2013, tradução nossa)

Os dados apresentados por Sguissardi (2015, p. 870) destacam, ademais, que o setor educacional foi o mais lucrativo na Bovespa em 2014:

De agosto de 2012 a agosto de 2014, por exemplo, enquanto o Ibovespa (índice do total de cerca de 350 empresas) teve uma redução de 3,67\%; a Vale (VALE5), redução de 13,48\%; e a Petrobras (PETR4), valorizaçáo de 9,32\% de suas açóes; a Kroton (KROT3) teve uma valorização de $314 \%$ e a Estácio (ESTC3), 240,97\% de suas respectivas ações.

A maior capacidade de captar recursos, via formas fictícias de capital, amplia significativamente o potencial dos negócios e, portanto, de rentabilidade associada à área educacional. Uma das principais consequências disso é o processo de concentração e centralização dos capitais, que abordaremos, nesta seção, adotando os conceitos de concentração e centralização formulados por Marx.

O primeiro relaciona-se ao crescimento de capitais individuais e de capitalistas; o segundo refere-se a uma redistribuição dos capitais já existentes, independentemente do crescimento do volume do capital social. Tais processos sáo complementares, segundo Marx (2013, p. 703): “[...] a acumulaçáo [...] é um procedimento extremamente lento se comparado com a centralização, que só precisa alterar o agrupamento quantitativo dos componentes do capital social.” 
$\mathrm{Na}$ atual etapa do desenvolvimento capitalista, o capital está mais concentrado do que em qualquer outro período; concentração reforçada pelo movimento de centralização mediante fusôes/aquisiçóes (CHESNAIS, 1997). Na contribuição de Netto e Braz (2009, p. 224), que analisam historicamente a constituição desses processos, temos a indicação de outra dimensão que é profundamente afetada, a do poder político:

[...] em consequência dessa concentração e centralização, os grupos monopolistas (ancorados em organizaçóes que se tornaram corporaçôes megaempresariais) desenvolveram interaçôes novas [...], nas quais a concorrência e a parceria encontram mecanismos de articulação que lhes asseguram um poder decisório especial. No topo dessas articulações, figura um restrito círculo de homens (e umas poucas mulheres) que constitui uma nova oligarquia, concentradora de um enorme poder econômico e político. ${ }^{8}$

Os autores ressaltam, ainda, que por meio dos lobbies desses grupos tomam-se decisôes que afetam a vida de bilhôes de homens e mulheres, "sem qualquer conhecimento ou participação destes." (NETTO BRAZ, 2009, p. 225) Além de seus dispositivos próprios, o grande capital instrumentaliza diretamente a açáo dos organismos internacionais (FMI, Banco Mundial, Organização Mundial do Comércio, Unesco e outros), impondo aos Estados, sobretudo os periféricos, os chamados 'ajustes estruturais', que vão de diretrizes macroeconômicas até reformas educacionais.

É nesse contexto mais amplo que vem ocorrendo, no Brasil, o que alguns autores denominam de tendência de oligopolização do ensino superior (SILVA JUNIOR; SGUISSARDI, 2005; SGUISSARDI, 2008, 2015; OLIVEIRA, 2009; CHAVES 2010). Trata-se de um processo de concentração e centralização, caracterizado por aquisições e fusões que dão forma a grandes conglomerados. Dados sistematizados pela consultoria Hoper Educação (2016, p. 102 - grifos do autor) apontam essa evidência:

O fenômeno da concentração de mercado no setor de educação privada no Brasil é uma realidade, que não terá retrocesso. Há 13 anos, os 20 maiores grupos educacionais detinham 
em torno de $14 \%$ do mercado, em relação ao total de alunos. Em 2015, estimamos que os 12 principais grupos educacionais concentram $43,9 \%$ da quantidade de matrículas em cursos de graduação (Presencial e EaD) e Pós-graduação.

[...]. Em conjunto, os quatro primeiros grupos educacionais do ranking detêm $33,9 \%$ de share de matrículas, ou seja, $1 / 3$ do total de matrículas no Brasil. A quantidade de instituiçóes pertencentes a esses quatro grupos é 219 , cerca de $10,5 \%$ do total de instituiçôes privadas de ensino superior.

Quando se diferenciam as atividades presenciais e a distância a situação é ainda mais evidente: das 92 instituiçóes privadas existentes, as 22 consideradas de grande porte concentravam $93 \%$ dos matriculados no EaD. Estudo da FGV sobre as 'S.A.' no mercado do ensino superior apontou que as várias formas de realização do $\mathrm{EaD}$ "são amplamente dominadas pelo setor privado e majoritariamente pelos grupos de capital aberto" (CALEFFI; MATHIAS, 2017, p. 78), tendo como uma das razóes mais relevantes o fato de que são grupos que estão capitalizados e que, por isso, conseguem investir no uso da tecnologia como forma de redução dos custos.

Ao reprovar a fusão entre Kroton e Estácio em 2017, o Cade alegou que a operaçáo geraria "vários níveis de concentração, inclusive com a formação de monopólios.” (MARTELLO, 2017) Não à toa, as empresas atuantes nesse setor ampliaram suas estratégias, avançando também para a educação básica. As recentes aquisições da Kroton - o Centro Educacional Leonardo da Vinci, em Vitória, e a Somos Educação, autodeclarado maior grupo de educação básica brasileira (CUNHA, 2018) - exemplificam isso.

No caso da educação básica privada, o movimento de concentração e centralização já estava presente, ainda que em menor dimensão se comparado ao ensino superior. Estudos desenvolvidos por Adriáo (2011), Cassiano (2013), Pinheiro (2014) e Galzerano (2016) apontaram essa tendência, com foco nas políticas destinadas ao provimento de materiais didáticos. A Somos Educação é o caso mais emblemático: desde que foi listada na Bovespa, em 2011, o grupo adquiriu, até o ano de 2015, mais de 25 marcas (GALZERANO, 2016) 
Outros fatores políticos também contribuíram para a formação desses conglomerados. Destacam-se as negociaçôes da Rodada Uruguai, que resultou na criação, em 1995, da OMC e do Acordo Geral sobre Comércio e Serviços (GATS), acordo que foi assinado por países membros da OMC com o intuito da liberalização progressiva dos serviços. Se, por um lado, o Brasil não aderiu à proposta de abrir o seu setor educacional, por outro lado, pouco ou nada fez para impedir a expansão do setor privado com fins lucrativos, legitimando (também por omissão) as fusões e aquisiçôes e a abertura de capital de grupos educacionais em bolsa de valores (TASQUETTO, 2016). Caminha na mesma direção o acordo sobre o comércio internacional de serviços, que vem sendo discutido por 50 países desde 2012. O Trade in Services Agreement (Tisa) objetiva promover e ampliar a desregulação e a liberalização do comércio, ignorando as regulaçóes e normativas estatais e beneficiando as corporações. Em 2016, o Brasil entrou para a negociação. (GALZERANO, 2016)

\section{Disputas pelo fundo público}

As disputas pelo fundo público no campo educacional, em tempos de predominância das formas fictícias do capital, não ocorrem de forma simples. Por isso, como apontado inicialmente, consideramos restrito o entendimento de que tais disputas e as formas de apropriação que dela decorrem representariam apenas um deslocamento da 'fronteira' entre a educação pública/estatal e a privada/não estatal.

Durante o processo de reforma do Estado na década de 1990 intensificou-se essa disputa também no campo ideológico, razão do questionamento sistemático de certas identidades instituídas, sobretudo aquela entre Estado e público. Trata-se de uma manipulação ideológica que pretende asseverar que Estado, sociedade civil e mercado são como 'setores' distintos, ocultando o fato de que, em cada um deles, as contradiçóes entre interesses públicos e privados se fazem presentes (MONTAÑO, 2008, p. 38). A consequência política mais importante dessa disputa foi a de promover a noção de que o setor mais apropriado para exercer funções públicas não é o Estado, mas sim o chamado 'terceiro setor' - na realidade o privado habi- 
litado a angariar e utilizar fundos públicos como plataforma para negócios -, nos termos da reforma, o denominado público não estatal.

Assim, uma das mudanças estratégicas operacionalizadas pela Reforma do Estado foi o progressivo desmonte dos serviços públicos instituídos e/ou referendados pela Constituição de 1988, por mais que tenham sido "historicamente limitados e socialmente seletivos." (FONTES, 2010, p. 244) Ainda para a autora, a estratégia de atribuir todos os problemas ao Estado tinha o intuito de "gerenciar de maneira privada, concorrencial e lucrativa, políticas públicas voltadas para a maioria da população.” (op.cit., p. 273) Do ponto de vista ideológico e político, as muitas desigualdades brasileiras não eram negadas, mas 'justificadas' por essas supostas incompetência, ineficácia e ineficiência estatais. $\mathrm{O}$ apoio da mídia foi decisivo na difusão dessas ideias.

Pelo lado econômico, a mudança no padrão de alocação do fundo público torna dominante o seu uso regressivo, isto é, a lógica de extrair parcelas crescentes dos recursos arrecadados para remunerar as formas de capital fictício. Na ideologia dominante, essa operação de espoliação de parcela da riqueza nacional é apresentada sob o eufemismo da busca pelo superávit primário e pelo ajuste fiscal. A economia política do acúmulo desses superávits é essencial para que o Estado remunere os capitais nacionais e internacionais investidos na lógica da acumulação parasitária, e seus impactos mais fortes são os que implicam reduçôes nos recursos alocados em políticas sociais. (BEHRING; BOSCHETTI, 2011, p. 166-168)

As repercussões sobre áreas sociais são diretas e profundas. A aprovação da Emenda Constitucional 95/20169 é o exemplo máximo dessa lógica hegemônica. Trata-se, porém, de uma construção de longa data, em que se observa a atuação ativa de frações da classe burguesa em órgãos decisórios, no caso da educação, nos conselhos, secretarias e outros, ou até mesmo no Ministério da Educação e no Congresso Nacional, no sentido de influenciar o debate em torno da construção e implementação das políticas públicas para a área. Também contam com apoio da mídia, de ONGs, de fundações e de institutos privados para propagar e legitimar suas propostas. (FREITAS, 2014)

Esses setores participaram ativamente da disputa em torno das propostas para elaboração do Plano Nacional de Educação (2014-2024), conseguindo em grande medida instituir estratégias de médio e longo prazo 
que implicam (implicarão, caso o Plano seja efetivamente implementado) maior margem de captura do fundo público para o setor privado. ${ }^{10}$ Alguns estudiosos entendem que essa reorganização entre fraçóes de classe permite qualificar o setor que atua em áreas como a educação como uma "nova burguesia de serviços." (RODRIGUES, 2007; NEVES, 2002) Noutros termos, uma fração da burguesia se converte em "setor parasitário privilegiado do processo de reforma do Estado e dos padróes de acumulaçáo vigentes" (MINTO, 2014, p. 285), relação fundada na redefinição de prioridades políticas e de alocação do fundo público. Para se ter uma ideia disso, as duas maiores empresas atuantes no ensino superior e na educaçáo básica brasileira, respectivamente, Kroton e Somos Educação, possuem em comum o fato de que grande parte de suas receitas advém do fundo público. O Fies respondia por 44\% da receita da Kroton, em 2014, correspondendo a cerca de 50,3\% de 'exposiçáo' ao programa nas matrículas presenciais (HOPER EDUCAÇÃO, 2016, p. 111) ${ }^{11}$; no mesmo ano, as políticas de aquisição e distribuição de materiais didáticos ${ }^{12}$ correspondiam a $61 \%$ da receita da Somos. (GALZERANO, 2016)

As conclusôes do Instituto de Pesquisa Econômica Aplicada, sobre as mudanças instituídas em 2015 no Fies, nos revelam outra dimensão da relação entre setor privado de ensino superior e fundo público:

[...] uma vez que o corte na oferta de contratos novos no Fies não foi acompanhado de redução semelhante do número de ingressantes, pode-se supor que uma parcela significativa de potenciais contratantes do Fies estava apta a ingressar na educação superior privada sem o aporte do financiamento estudantil, e que as regras de contratação do Fies, vigentes no período 2010-2014, suscitaram a ocorrência de um efeito crowding-out, uma vez que ofereciam financiamento com taxa de juros mais baixa que a rentabilidade do mercado financeiro, inclusive a da caderneta de poupança. Com isso, parcela significativa dos estudantes teria optado pelo contrato junto ao Fies ao longo desse período, mesmo dispondo de capacidade financeira para arcar com o pagamento das mensalidades escolares. (IPEA, 2017, p. 35-36) 
Os dados indicados permitem concluir que o programa funcionava também como uma forma de 'trocar' o pagamento regular das mensalidades dos estudantes pelo financiamento a baixo custo do Fies, em claro benefício para as instituiçôes.

Não bastasse esse movimento, a própria Somos Educação foi adquirida pela Kroton em 2018, demonstrando nova estratégia de atuação dessa empresa, que agora expande sua atuação para a educação básica, num contexto em que as matrículas no ensino superior apresentam tendência de estagnação e os contratos com o Fies estáo em queda. Por sua vez, na educação básica, as políticas de provimento de materiais didáticos estão em ritmo crescente, sobretudo após a homologação, em 2018, da Base Nacional Comum Curricular referente à educação infantil e ao ensino fundamental.

\section{Consideraçóes finais}

A crítica que tem sido empreendida aos processos de financeirização da educação, seja no nível superior ou na educação básica, são necessárias e inadiáveis no contexto atual. Mas um alerta se faz importante. Deve-se evitar o equívoco assinalado por Prado (2014) naquilo que ele considera a 'tese canônica' ${ }^{13}$ sobre a financeirização, que tem influenciado tais debates no campo econômico. Para o autor, quando a análise perde de vista a totalidade do capital enquanto forma social dominante, recorrendo a uma espécie de hierarquização arbitrária e até moral entre capitais (produtivo $\mathrm{x}$ improdutivo; industrial $\mathrm{x}$ financeiro; normal $\mathrm{x}$ disfuncional), também se perde de vista a sua unidade fundamental: "as diferentes formas do capital portador de juros devem ser apresentadas como diferenciaçóes constitutivas da totalidade do capital, as quais têm funcionalidades próprias na organização das relaçóes capitalistas de dominação." (PRADO, 2014, p. 22-23) Portanto, trata-se de uma crítica superficial "pensar que certos capitais têm - e que outros não têm - legitimidade na apropriação de excedente com base em critérios de ordem funcional ou mesmo moral." (op.cit., p. 24)

Desse modo, nos termos de uma análise do campo educacional, é mister compreender que a centralidade do capital fictício, bem como seu 
favorecimento aos processos de concentração e centralização, não implica que uma forma 'pior' de acumulação vem a dominar as atividades educacionais, impondo suas demandas ao fundo público. Trata-se do desenvolvimento do modo de produção capitalista e de sua lógica predatória, incontrolável e sempre expansível. Mudam-se as formas, potencializando o seu fetichismo e sua própria percepção, mas a sua natureza social, enquanto capital, permanece a mesma.

O que há de novo é o modo pelo qual a dominação financeira se apresenta frente às atividades educacionais, impondo-lhe controles e dinâmicas cujo centro irradiador é externo e regulado globalmente nos grandes mercados financeiros, isto é, na forma da distribuição dos ganhos capitalistas provenientes dos setores em que a mais-valia é produzida. Nos termos de Prado (2014, p. 29), a financeirizaçáo "indica que o sistema do capital atingiu a sua realização suprema no curso da história." Poderíamos dizer, em consequência, que a educação se torna meio - como qualquer outra mercadoria - para a realização de lucros capitalistas (em grande escala), aquilo que Marx já afirmara no Livro I d'O Capital, a saber, que em nada se altera a relação fundamental do capital se este é investido numa fábrica de salsichas ou de ensino. (MARX, 2013, p. 578)

Com a financeirização, amplia-se significativamente o montante disponível de capitais para ser adiantado às atividades no mercado educacional. O resultado disso é uma dupla sobreposição do interesse privado sobre a educação, pois, além de as empresas educacionais terem nas suas atividades um meio para a obtenção de lucros, também os investidores do setor financeiro - inclusive estrangeiros - o terão. Ambos entram na divisão da mais-valia produzida socialmente (GALZERANO, 2016). O Estado não é secundário nesse processo, apesar da proclamada defesa neoliberal por sua 'minimalização'. Políticas como o Fies, Prouni, Pronatec e o PNLD, financiadas pelo fundo público, por isso, se tornam mecanismos fundamentais para que as empresas privadas garantam sua rentabilidade, bem como a do conjunto de capitais investidos nas suas atividades. E quanto mais as estratégias dos grupos educacionais se misturam com o poder econômico e político criado pelo capital fictício, maior sua capacidade de captura do fundo público, mesmo quando não há, propriamente, uma variação na proporção entre matrículas ou instituições públicas e privadas. Eis a complexidade do processo de privatização na fase contemporânea do capitalismo. 
Soma-se a ela outra dimensão, a da disputa crescente pelo controle das instituiçôes educativas, haja vista que o interesse de setores burgueses em relação à escola não deixa de estar baseado na dupla dimensão que envolve, dialeticamente, os conteúdos - valorativo, cultural e ideológico - do ensino, por um lado, e a preparação para o mercado de trabalho, por outro lado. ${ }^{14}$

Em síntese, o interesse privado no campo educacional contemporâneo está permeado por uma maior abrangência do capital em relação a toda a sociabilidade humana, numa situação em que as atividades educacionais podem se tornar espaços privilegiados para a acumulação, seja na forma direta do mercado ou do chamado terceiro setor, seja pela influência sobre as políticas e a organização da educação estatal. Mas, como qualquer outra esfera da atividade humana, a educação não está condenada fatalmente ao jugo dos interesses da acumulaçáo capitalista. Formas de resistência e de luta contra hegemônicas (ocupaçóes, greves, formação de coletivos de professores/as e estudantes, lutas sindicais e outras) também compóem o cenário do desenvolvimento educacional atual, mantendo-o contraditório e aberto.

\section{Notas}

1 Autores em distintos contextos e sob diferentes perspectivas discutem a privatização da educação, Destacamos Dale (1994), Belfield e Levin (2002), Ball e Youdell (2007), Robertson e Verger (2012).

2 Ainda que não seja do escopo deste artigo, é fundamental lembrar que a relação entre Estado e acumulação não é mecânica e rígida. Ao longo da experiência histórica, as lutas e conflitos sociais instituem formas de oposição a esse movimento, promovendo uma retração na base de exploração que o capital consegue viabilizar por meio da ação estatal e da exploração da força de trabalho.

3 Tem-se aí um processo que alguns autores denominam de despolitização da 'questão social'. Sobre isso, ver Oliveira (2007), Montańo (2008), Pinassi (2011), Netto (2013).

4 Marx (1991) afirma que há uma tendência gradual de queda na taxa média de lucro, já que o desenvolvimento das forças produtivas, sob o modo de produçáo capitalista, tende a reduzir o dispêndio de capital naquilo que é o elemento gerador de valor (e mais-valia): a força de trabalho. Para o autor, entretanto, esta é uma tendência e, como tal, sujeita à análise na concretude histórica e no decurso de longos períodos. Além disso, a análise da realidade histórica apresenta fatores de contra tendência à lei. O investimento no setor financeiro é um desses fatores. Para mais informaçôes, ver o livro III d'O Capital, em especial os capítulos 13, 14 e 15.

5 Destacamos Foster (2007); Duménil e Lévy (2011); Harvey (2013); Shaikh (2011), Carcanholo e Sabadini (2009).

6 Para discussão mais aprofundada faz-se essencial a leitura de Marx (1991), bem como de estudiosos contemporâneos como Prado (2014) e aqueles reunidos em Gomes (2015).

7 Diferentes ediçôes d'O Capital traduzem termos importantes da obra de formas distintas. As 
ediçóes aqui mais utilizadas, como as da Editora Civilização Brasileira (Marx, s/d; Marx, 1991), adotam a expressão capital produtor de juros. A despeito disso, optamos pela utilizaçáo da traduçấo capital portador de juros, presentes nas ediçôes das editoras Nova Cultural e Boitempo.

8 Paulani (2008, p.124) afirma que, no capitalismo contemporâneo, "uma série de setores econômicos [são] dominados mundialmente, na maior parte dos casos, por não mais que uma dezena de grupos empresariais."

9 Aprovada em 2016, institui um 'novo regime fiscal', que, dentre outras consequências, prevê um congelamento de até 20 anos nos gastos destinados às políticas sociais.

10 Para uma leitura desse processo no caso da Educação Superior, ver Minto (2018).

11 Somente a Kroton possuía, em 2014, 18,1\% de todas as matrículas vinculadas ao Fies.

12 Referimo-nos à venda de livros didáticos, com destaque para o Programa Nacional do Livro Didático (PNLD), cuja presença da Somos Educaçấo é majoritária, ao menos desde 2010, atuando por meio das editoras Ática, Scipione e Saraiva; e à política de adoção dos chamados sistemas privados de ensino, em que a Somos atua com nove diferentes marcas. Ambos os tipos de materiais (livros didáticos e Sistemas) são fornecidos paras as redes públicas e privadas de ensino.

$13 \mathrm{O}$ autor se refere às ideias de François Chesnais.

14 Não foi objetivo deste artigo o aprofundamento das questôes que envolvem a dimensão formativa da educaçấo. É importante pontuar, no entanto, que diferentes fraçôes da burguesia possuem projetos distintos para a educação, não sendo correto reduzir o interesse privado nesse campo apenas ao 'negócio educacional'.

\section{Referências}

ADRIÃO, T. (Coord.). Sistemas apostilados de ensino e municípios paulistas: o avanço do setor privado sobre a política educacional local. 2011. 109 p. Relatório de Pesquisa - Unicamp.

BALL, S.; YOUDELL, D. Hidden privatization in public education. Education International: 5th World Congress, July 2007.

BEHRING, E. R.; BOSCHETTI, I. Política social: fundamentos e história. 9. ed. São Paulo: Cortez Editora, 2011. v. 2.

BELFIELD, C.; LEVIN, H. Education privatization: causes, consequences and planning implications. Paris: Unesco, 2002.

BRAZ NETTO, J. P, M. Economia política: uma introdução crítica. 5. ed. vol. 1. São Paulo: Cortez, 2009.

CALEFFI, Paula; MATHIAS, Alexandre. Universidade S. A.: as companhias de capital aberto da educação superior no Brasil. Rio de Janeiro: FGV Editora, 2017.

CARCANHOLO, R.; SABADINI, M. Capital fictício e lucros fictícios. Revista da Sociedade Brasileira de Economia Política, Rio de Janeiro, n. 24, p. 41-65, jun. 2009. 
CARVALHO, C. H. A. A mercantilização da educação superior brasileira e as estratégias de mercado das instituiçóes lucrativas. Revista Brasileira de Educação, Rio de Janeiro, v. 18, n. 54, p. 761-776, jul./set., 2013.

CASSIANO, C. F. O mercado do livro didático no Brasil do século XXI: a entrada do capital espanhol na educação nacional. SP: Editora Unesp, 2013.

CHAVES, V. L. J. Expansão da privatização/mercantilização do ensino superior brasileiro: a formação dos oligopólios. Educação e Sociedade, Campinas, v. 31, n. 111, p. 481-500, abr./jun. 2010.

CHESNAIS, F. Capitalismo de fim de século. In: COGGIOLA, O. (Org.). Globalização e socialismo. São Paulo: Xamá, 1997.

CUNHA, J. Conglomerados do ensino superior avançam sobre a educação básica. Folha de S. Paulo, Mercado, 17 jun. 2018. Disponível em: <https://www1.folha. uol.com.br/mercado/2018/06/conglomerados-do-ensino-superior-avancam-sobre-aeducacao-basica.shtml>. Acesso em: 13 set. 2018.

DALE, R. A promoção do mercado educacional e a polarização da educação. Educação, Sociedade \& Culturas, Porto, n. 2. p. 109-139, 1994.

DUMÉNIL, G.; LÉVY, D. The crisis of early 21st century: a critical review os alternative interpretations. Disponível em: <http://www.jourdan.ens.fr/levy/>. Acesso em: out. 2014.

FONTES, V. O Brasil e o capital-imperialismo: teoria e história. 2. ed. Rio de Janeiro, Editora UFRJ, 2010.

FOSTER, J. B. The Financialization of Capitalism. Monthly Review, 58, 11; p. 1-12, apr. 2007.

FREITAS, L. C. Os reformadores empresariais da educação e a disputa pelo controle do processo pedagógico na escola. Educação e Sociedade, Campinas, v. 35, n. 129, p. 1085-1114, out./dez. 2014.

GALZERANO, L. S. Grupos empresariais e educação básica: estudo sobre a Somos Educação. 2016. 167p. Dissertação de mestrado - Faculdade de Educação da Universidade Estadual de Campinas, Campinas.

GOMES, H. (Org.). Especulação e lucros fictícios: formas parasitárias da acumulação contemporânea. São Paulo: Outras expressóes, 2015. . Introdução. In: . (Org.). Especulação e lucros fictícios: formas parasitárias da acumulação contemporânea. São Paulo: Outras expressóes, 2015a, p. 13-29.

HARVEY, D. O neoliberalismo: história e implicaçóes. 3. ed. São Paulo: Loyola, 2012. . Os limites do capital. São Paulo: Boitempo, 2013.

HERRERA, R. Prefácio: o capital fictício no centro da crise. In: GOMES, H. (Org.). Especulação e lucros fictícios: formas parasitárias da acumulação contemporânea. São Paulo: Outras expressóes, 2015. 
HOPER EDUCAÇÃO. Análise setorial da educação superior privada - Brasil. [Paulo Presse (Org.)]. Foz do Iguaçú, PR, jun. 2016.

INSTITUTO DE PESQUISA ECONÔMICA APLICADA. Políticas sociais: acompanhamento e análise - n. 25. Brasília, DF: IPEA, 2017. Disponível em: <http:// www.ipea.gov.br/portal/index.php?option=com_content $\& v i e w=$ article $\&$ id $=31656 \&$ Ite mid=9>. Acesso em: 08 out. 2018 .

MARQUES, R.; NAKATANI, P. Crise, capital fictício e afluxo de capitais estrangeiros no Brasil. Caderno CRH, Salvador, v. 26, n. 67, p. 65-78, jan./abr. 2013.

MARTELLO, A. Cade reprova compra da Estácio pela Kroton Educacional. G1, Economia, 28 jun. 2017. Disponível em: <https:/g1.globo.com/economia/negocios/noticia/ cade-reprova-compra-da-estacio-pela-kroton-educacional.ghtml>. Acesso em: 25 nov. 2017.

MARX, K. O Capital: crítica da economia política. Livro I: o processo de produção do capital. São Paulo: Boitempo, 2013.

- O Capital: crítica da economia política. Livro 3: o processo global de produçáo capitalista. v. 4. 6. ed. Rio de Janeiro: Civilização Brasileira, 1991.

- O Capital: crítica da economia política. Livro 3: o processo global de produção capitalista. v. 5. Rio de Janeiro: Civilização Brasileira, s/d.

MINTO, L. A educação da miséria: particularidade capitalista e educação superior no Brasil. São Paulo: Outras Expressóes, 2014.

. Educação superior no PNE (2014-2024): apontamentos sobre as relaçóes público-privadas. Rev. Bras. Educ., Rio de Janeiro, v. 23, Epub. fev. 2018.

. Governo e educação novamente golpeados: consequências para o nível superior e o trabalho docente. In: MACEDO; NOVAES; LIMA FILHO (Org.). Movimentos sociais e crises contemporâneas. Vol. 3. Marília, SP: Lutas Anticapital, 2018a. p. 293-309.

MONTAÑO, Carlos. Novas configuraçóes do público e do privado no contexto capitalista atual: o papel político-ideológico do "terceiro setor". In: ADRIÃO, T.; PERONI, V. (Org.). Público e privado na educação: novos elementos para o debate. Sáo Paulo: Xamá, 2008. p. 27-49.

NETTO, J. P. Uma face contemporânea da barbárie. Novos Rumos, Marília, v. 50, n. 1, jan.-jun. 2013.

NEVES, L. M. W. (Org.). O empresariamento da educação: novos contornos do ensino superior no Brasil dos anos 1990. São Paulo: Xamã, 2002.

OLIVEIRA, F. de. Política numa era de indeterminação: opacidade e reencantamento. In: OLIVEIRA, F.; RIZEK, C. (Org.). A era da indeterminação. São Paulo: Boitempo, 2007. p. 15-45.

OLIVEIRA, R. P. A transformação da educação em mercadoria no Brasil. Educação e Sociedade, Campinas, v. 30, n. 108, p. 739-760, out. 2009. 
PARRA-BERNAL, G.; SCHINCARIOL, J. Brazil education sector to boost bankers' dealflow. Reuters, Business, Sep. 4, 2013. Disponível em: <http://www.reuters.com/ article/us-brazil-education-finance-idUSBRE9830EH20130904\#YsPvVccwPzYr8L AQ.97>. Acesso em: 04 dez. 2015.

PAULANI, L. Brasil Delivery: servidão financeira e estado de emergência econômico. São Paulo: Boitempo, 2008.

PINASSI, M. O. O lulismo, os movimentos sociais no Brasil e o lugar social da política. Lutas Sociais, São Paulo, n. 25/26, p. 105-120, 2. sem. 2010 e 1. sem. 2011.

PINHEIRO, D. Educação sob controle do capital financeiro: o caso do Programa Nacional do Livro Didático. 2014. 128 f. Dissertação (Mestrado em Educação) Faculdade de Educação da UFRJ.

PRADO, Eleutério. Exame crítico da teoria da financeirização. Crítica marxista, Campinas, n. 39, p. 13-34, 2014.

ROBERTSON, S.; VERGER, A. A origem das parcerias público-privada na governança global da educação. Educação e Sociedade, Campinas, v. 33, n. 121, p. 1133-1156, out./dez. 2012.

RODRIGUES, José. Os empresários e a educação superior. Campinas: Autores Associados, 2007.

SGUISSARDI, V. Educação superior no brasil: democratização ou massificação mercantil? Educação e Sociedade, Campinas, v. 36, n. 133, p. 867-889, out./dez., 2015. . Modelo de expansão da educação superior no Brasil: predomínio privado/

Recebido em Io out. 2018 / Aprovado em I2 nov. 2018

\section{Para referenciar este texto:}

GALZERANO, L. S.; MINTO, L. W. Capital fictício e educação no Brasil: um estudo sobre a lógica contemporânea da privatização. EccoS - Revista Científica, São Paulo, n. 47, p. 6I-80. set/dez. 2018. Disponível em: <https://doi.org/I0.5585/ EccoS.n47.10740>. 